\title{
Implementation of Online E-Auction to Overcome the Problem of Corruption with Effective and Efficient Procurement with Transparency
}

\author{
Darpan Anand ${ }^{a}$ \\ Associate Professor, Chandigarh University, Garuha, Punjab, India
}

Article History: Received: 11 January 2021; Accepted: 27 February 2021; Published online: 5 April 2021

\begin{abstract}
This research paper explores the concept of eAuction, an increasingly form of online procurement. There is fixed delivery policy.This is a fully dynamic system which can be easily operated by the users. This research paper explores all the increasing form of online procurement. Online e auction system is gaining popularity day by day because of its ease of making online bidding and selling or buying. Users can freely go the website and register there and it's ready for selling or buying their product. The main thing that is needed to be there is trust among the users, so that they can easily register and take part in the process without having any doubt regarding security. The aim of any online system are related with two points that are Customer satisfaction and Business purpose. Therefore, to meet these requirements there must be need of making enhancements in the online auction system. This paper will explore the all forms of online procurement that we can make to improve the current system.
\end{abstract}

Keywords: E -Auction, Web Communication, Application level protocols, Information Security

\section{Introduction}

Online e auction system is a system that provides online platform for the people to buy ,sell and take participation in the bidding process of products. It is the system that provides comfort to the users and also add much value to the e-commerce market worldwide.[1][2][3]

It is the trading merchandise that is providing services for the development of e-commerce worldwide through web services. Thus building the connection and trade between the dealer and consumer that can be also refer to as business to consumers (B2C).[4][5]

Also, e auction relaxes the money expenses and provides reliability for the users. Users are promoting it as it facilitates them to buy and sell product and to set the bidding process without going anywhere and thus also relaxing them from the expenses with the instantaneous internet service providing information about each and every aspect clearly with full security support. It is the result of developed e commerce market (EC) that users are giving approval to it, which ultimately increases the value of e auction. It provides cost optimization as less resources are needed and provides the ease of work.[6] [7]

Broadly, e auction are categorised into different categories depending upon the different procedures they follows and they have been proposed and they are:

(1) forward auction that is also known as( English auction),In forward auction the bids are thrown in the ascending order i.e the lowest bid is mentioned at first and then the bid amount increases and it increases till the highest bid, if no other person is ready to give the highest amount than that,then it is the last bid and the product is sold at that highest price.

(2) reverse auction that is also known as( Dutch auction).Reverse auction is same as of forward auction but the difference is that in this bids are thrown in descending order of price, first they throw highest price and if nobody is ready to pay that amount then they decrease the amount. And in last the amount at which the user is ready to pay is the last bid and he won.

3) Vickery auction in which winner has to pay the last runner up price i.e the second highest price that is last.lt is like in this along with the secured price that the winner has fixed. He also have to give the last runner up amount.

(4) Sealed bid auction in which the prices are set and all the bids are given to the auctioneer, where auctioneer opens up all the bids that are being given to him and the bid which has highest price wins the auction that is the final price for the given product.

(5) Continues double auction (CDA) which enables all the buyers to pay the amount for all the bids like for the favourable products It is the process like we invest in share markets.

So, these are the bids that are being proposed in which the most widely used are forward auction and reverse auction that are the most widely used options therefore to implement them in software and make them better for the user is necessary to maintain the demand for the online auction system So, there is high competition in market as there are a huge number of online systems that are available worldwide .So, it is necessary to maintain the 
security and trust of the user so that no fraud practices will be followed as trust is the main concern for the users. So, that no loss has to be faced by them. Apart from this there is need to go and break the wall and get some new ways and ideas to implement into the existing systems to make them work better than before and that too facilitates the users. And also gain popularity and increases demand of the system So, that e commerce will grow worldwide with the higher business development ratio and also the customer satisfaction. So here we go for the related work section i.e (2) which includes case study and related work that have been proposed. And after that our approach or se can say proposed work in section [8], [9]

(3) which includes betterment ideas , after that there will be result in section (4) followed by conclusion in the last i.e section (5).

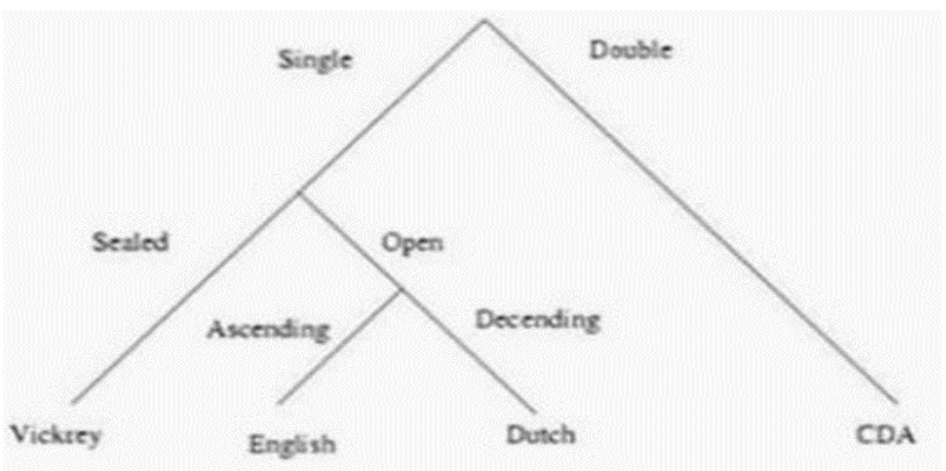

\section{Related work}

Figure 1: Nomenclature of components of e-Auction process

With a market capitalization of approximately $\$ 6.6$ billion in 2019 , a new report compiled by Technavio, a technology market research company, indicates that the global e-Auction market size could reach nearly 28 billion by 2024 . The new study also shows that the global e-Auction may register nearly Compound Annual Growth Rate of $7.2 \%$ during the forecast period. Against this background, it is evident that the e- Auction industry is set to expand rapidly in the near future. As $\mathrm{Xu}$ and Tembine delineates, e-Auction is an aspect of electronic commerce conducted by way of internet procurement. This kind of trading technology has increasingly become a standard mechanism for retailers and consumers across businesses [10]. Moreover, Chen, Xing, Qiu and Li note that the popularity of this technology stems from the fact that the internet offers a comprehensive market information as well as the requisite infrastructure for the execution of auctions at relatively lower costs.[11]

Today, there are two common types of eAuction model, which were designed by Timothy Leunga and William Knottenbeltb. These models include the for forward auction' and the 'for reverse auction,' which typically defines the mechanisms associated with bidding as well as the accompanying results.

\subsection{Forward auction}

In the forward auction model, the user makes a query of the merchandise of choice or makes an announcement of a new one, and the system checks the status of the query to ascertain whether the user is a consumer or a dealer. According to that it takes decision further [12]

\subsection{Reverse auction}

On the other hand in reverse auction everything else just works same as the forward auction but except for that when system checks the status of the query it is firstly decided that whether the user is consumer or dealer and then the system checks the query according to that. These are the most common models for e auction that are being implemented as discussed in the introduction section (1).

\subsection{Case study (E bay)}

In existing models, we have an online website that is [BAY which facilitates by providing the same platform for the user to sell ,bid and also buy the products . eBay is highly used website, it has amazing features, we can buy and sell from the same platform as soon as bids gels over . eBay will notify you by sending the email. eBay is also verified application that provides security to the users by authentication of their email ids. It has almost everything that an online auction application must have but apart fro this. Emails verification could also be proven fakes by some frauds and which can lead to harm in public money and trust on the application but it is the power and plus point of the online system that it gains popularity by advertising and also have numerously large numbers of users. So , to overcome this problem we have new proposed model and also the new features that to be used enhance the model. 


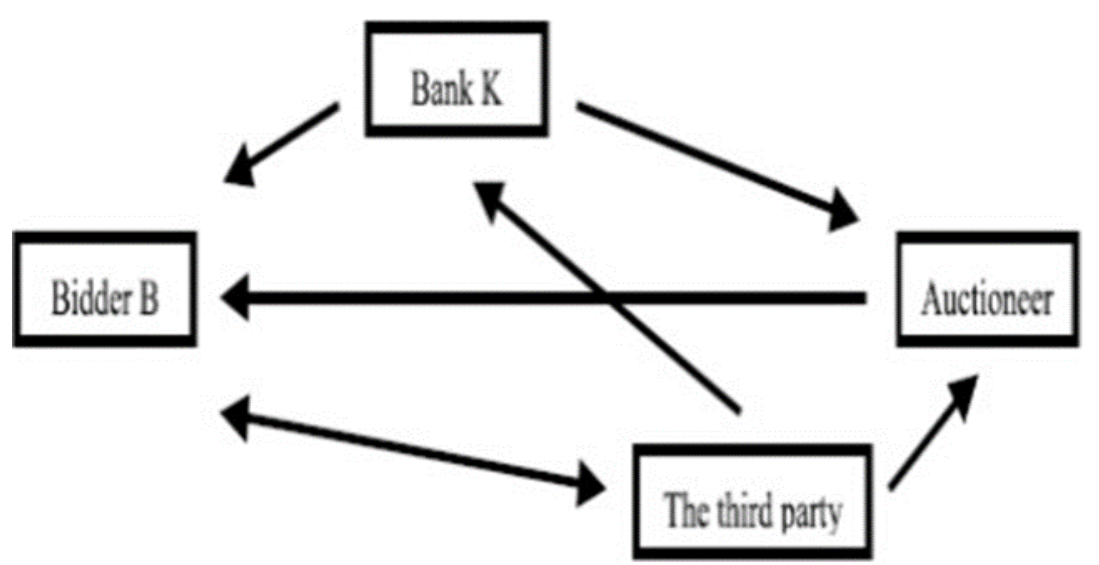

Figure 2:- The process flow of the e-Auction process

\section{Proposed work}

In proposed model, we mainly talk about the improvements and extra additions to the existing model, so here we talk about three main things that are trust and its significance and also how navigation support system will build security ,trust and reliability and feedback and new ideas column that will let us know about what user think of our services and also the new things that they want in our system that will give us brief idea about how to improve which ultimately results in betterment and growth.

Also proposed model definately means to add something new in an existing model or system ,that doesn't mean that it's the implementation that has to be done. In proposed model we give ideas that how we can enhance our model or how we can make it better so,here three features are:

\subsection{Trust and security}

Trust is the basis of any contract and is main thing in the business and for the transaction purposes. And there are many fraud practices out there which can create harm to the trust of the users and also will led us facing loss . So, to overcome this registration security model should introduce which will work at the registration time itself that means user will get access to use the system only when he/she is authorised and valid then only unique registration ID will be given to them. For being the valid user you need to confirm your official email ids and all the information about yourself then the confirmation link has been send to the email ids and after clicking that link the person has to give their official government I'd proof which will be accepted in computerized way ,after confirming all the essential details the user will get their unique Id and will be considered registered user or else not allowed to access the system. This will maintain the trust among users and also ensure security and prevent fraud practices.

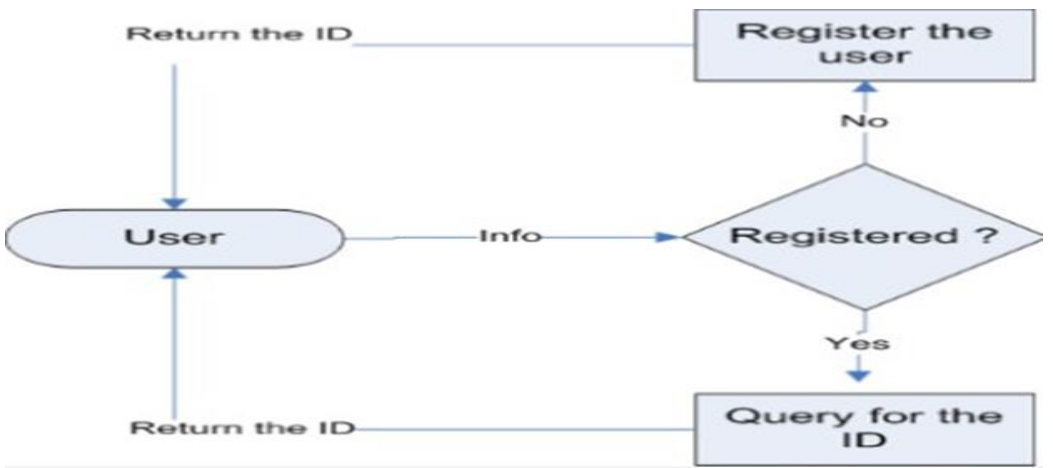

Figure 3: Proposed model for registration process

\subsection{Feedback and suggestions column:-}

Secondly, we should add the feedback column to the design as it is the must,so that we could understand what are the requirements of the majority users and also what are the bads and goods for the system and also if users want to give some new ideas or features in the system ,then we will also have the good sources of ideas for the betterment of the model. Also ,like other sites they have chat options ,we can also make feedback column inside our system only in which user can only give their suggestions for the improvement and also the new ideas. They don't have to go to any other place, they can get that feedback and suggestions column like when they are registered users during auctioning process meanwhile at the same platform they can also have that suggestion option without the wastage of time.

\subsection{Navigation support}

Thirdly, navigation support this is the new for online auction but also quite common for the food delivery applications . Yes, navigation support we can also add the navigation support feature in our model which facilitates users and also can maintain security of the user's data. In this, when the deal is done and the highest bids is done then navigation support feature can be used by the seller and the buyer with their permissions ,if they grant 
permission to access their location then only this feature will navigate the seller to reach his destination that is buyers address. This will add to the great features of the model. And also it will ensure security that when we enable share location option like we have in WhatsApp that share live location . Then it will help to navigate the address and also ensure that whether the given address is valid or not by checking the location that is being shared This aids to the best practices for security and also ease to reach the destination and only after that the payment is done by the buyer and the amount reaches to the bank then it is the duty of the auctioneer i.e third party to mark the status of the product is sold. And then using navigation option they can easily send the product to its destination. Moreover, it will also help in the authentication of the valid address which will ensure security and trust we can add this option to our website like we have sharing live location in our WhatsApp

We require Gaggle development kits to made this work, we can use android development part and also system development part and will be using codes and algorithms like we use html code to get the navigation support. It's the sample code that will share your address to whom you want to share it.

HTML Code:

<form action=littp:/Raps.google.comfmaps" method=i4ger target="bianr> Enter your starting address:

$<$ gputtype=atext" name="saorde i $>$

$<$ input type="hidden" name=liaddevalue=w854 Deerfield Rd, Allen, nr,'

<input type=-submit" value=Pget directions' </form:

So, these are the features that can be added to this model. And this is the proposed model that is to be in queue for serving the users.

\section{Results and analysis :-}

The result of this research paper is that now we can have the system that is way strong and advanced than before and also will focuses on the main concern of the people worldwide. Also, the main issue i.e trust and security has been taken under noticed in more effective ways followed by the facilitation options like navigation and suggestions bar. This will give 'all in one ' options in single platform i.e in our online auction system .

\section{Conclusion:-}

In this effort, the most commonly used online auction system that are being used worldwide are discussed i.e forward auction and reverse auction with all the possible enhancement that could be done and also maintain the security and trust concern. We learn all other types of auction in detail and also we discussed that how the security issue can be resolved by giving model for registration phase other than just confirming emails. This model will ensure whether the user is buyer or seller or the third party i.e auctioneer ,they all have to register themselves with valid proofs and data. This will ensure trust and prevent many fraud and malicious practices by the sellers or third party by building communications at different phases during the auction process.

\section{References}

1. Albrecht, C. C., Dean, D. L., \& Hansen, J. V. (2005). Marketplace and technology standards

2. Chen, X., Xing, L., Qiu, T., \& Li, Z. (2017). An auction-based spectrum leasing mechanism for mobile macro-femtocell networks of IoT. Sensors, 17(2), 380.

3. Das, R., Hanson, J. E., Kephart, J. O., \& Tesauro, G. (2001, August). Agent-human interactions in the continuous double auction. In International joint conference on artificial intelligence (Vol. 17, No. 1, pp. 1169-1178). Lawrence Erlbaum Associates Ltd.

4. for B2B e-commerce: progress, challenges, and the state of the art. Information \& Management, 42(6), 865-875.

5. Javalgi, R., \& Ramsey, R. (2001). Strategic issues of e-commerce as an alternative global distribution system. International marketing review.

6. King, D. N., \& King, D. N. (2004). Introduction to e-commerce. Prentice Hall.

7. Liu, Y., Li, H., Peng, G., Lv, B., \& Zhang, C. (2015). Online purchaser segmentation and promotion strategy selection: evidence from Chinese E-commerce market. Annals of Operations Research, 233(1), 263-279.

8. Schulze-Horn, I., Pulles, N., Schiele, H., \& Scheffler, P. (2018). Using mechanism design theory in negotiations to improve purchasing performance. International journal of procurement management, 11(6), 777-800.

9. Subramani, M., \& Walden, E. (2001). The impact of e-commerce announcements on the market value of firms. Information Systems Research, 12(2), 135-154.

10. Subramani, M., \& Walden, E. (2001). The impact of e-commerce announcements on the market value of firms. Information Systems Research, 12(2), 135-154.

11. Teich, J. E., Wallenius, H., Wallenius, J., \& Zaitsev, A. (2006). A multi-attribute e-auction mechanism for procurement: Theoretical foundations. European Journal of Operational Research, 175(1), 90-100.

12. Wang, J., Wang, Q., Zhou, N., \& Chi, Y. (2017). A novel electricity transaction mode of microgrids based on blockchain and continuous double auction. Energies, 10(12), 1971.

13. Zhang, Y., Bian, J., \& Zhu, W. (2013). Trust fraud: A crucial challenge for China's e- commerce market. Electronic Commerce Research and Applications, 12(5), 299-308. 